\title{
Liquid Contact-Selective Potentiometric Sensor Based on Imprinted Polymeric Beads Towards $17 \beta$-Estradiol Determination
}

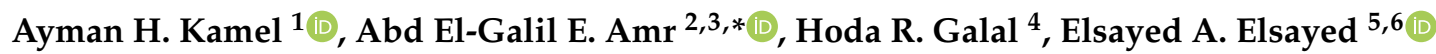 \\ and Ahmed I. Al-Sayady ${ }^{5}$ \\ 1 Department of Chemistry, Faculty of Science, Ain Shams University, 11566 Cairo, Egypt; \\ ahkamel76@sci.asu.edu.eg \\ 2 Pharmaceutical Chemistry Department, Drug Exploration \& Development Chair (DEDC), \\ College of Pharmacy, King Saud University, Riyadh 11451, Saudi Arabia \\ 3 Applied Organic Chemistry Department, National Research Center, Dokki, 12622 Giza, Egypt \\ 4 Inorganic Chemistry Department, National Research Center, Dokki, 12622 Giza, Egypt; hrgalal@hotmail.com \\ 5 Bioproducts Research Chair, Zoology Department, Faculty of Science, King Saud University, \\ Riyadh 11362, Saudi Arabia; eaelsayed@ksu.edu.sa (E.A.E.); 439105516@student.ksu.edu.sa (A.I.A.-S.) \\ 6 Chemistry of Natural and Microbial Products Department, National Research Centre, Dokki, \\ 12622 Cairo, Egypt \\ * Correspondence: aamr@ksu.edu.sa; Tel.: +966-565-148-750
}

Received: 11 June 2020; Accepted: 2 July 2020; Published: 7 July 2020

\begin{abstract}
Novel potentiometric devices "ion-selective electrodes (ISEs)" were designed and characterized for the detection of $17 \beta$-estradiol (EST) hormone. The selective membranes were based on the use of man-tailored biomimics (i.e., molecularly imprinted polymers (MIPs)) as recognition ionophores. The synthesized MIPs include a functional monomer (methacrylic acid (MAA)) and a cross-linker (ethylene glycol dimethacrylic acid (EGDMA)) in their preparation. Changes in the membrane potential induced by the dissociated $17 \beta$-estradiol were investigated in $50 \mathrm{mM}$ $\mathrm{CO}_{3}{ }^{2-} / \mathrm{HCO}_{3}{ }^{-}$buffer solution at $\mathrm{pH}$ 10.5. The ion-selective electrodes (ISEs) exhibited fast response and good sensitivity towards $17 \beta$-estradiol with a limit of detection $1.5 \mu \mathrm{M}$ over a linear range starts from $2.5 \mu \mathrm{M}$ with an anionic response of $61.2 \pm 1.2 \mathrm{mV} /$ decade. The selectivity pattern of the proposed ISEs was also evaluated and revealed an enhanced selectivity towards EST over several phenolic compounds. Advantages revealed by the presented sensor (i.e., wide range of assay, enhanced accuracy and precision, low limit of detection, good selectivity, long-term potential stability, rapid response and long life-span and absence of any sample pretreatment steps) suggest its use in routine quality control/quality assurance tests. They were successfully applied to estradiol determination in biological fluids and in different pharmaceutical preparations collected from the local market.
\end{abstract}

Keywords: potentiometry; man-tailored mimics; MIPs; $17 \beta$-estradiol; biological fluids

\section{Introduction}

$17 \beta$-Estradiol is a natural estrogen belonging to the natural steroidal hormones. This class of hormones is essential in the reproductive processes of females and decisively affecting mammal fertilization. In addition, it controls numerous physiological actions, especially in women. Some of these are body growth, menstruation, minerals, carbohydrates, protein, and fat metabolism. It also has an important role in males including in bone and sperm formation [1-3]. Low concentrations of estradiol in the human body can lead to developmental abnormalities and damage to the male reproductive system [4]. 17ß-Estradiol poses a real risk to children in early puberty and also increases 
the risk of breast and ovarian cancer in women [5]. Some other diseases are related to this hormone, such as bladder cancer [6] and Alzheimer's disease [7,8]. Mammals secrete this hormone and its derivatives daily through urine, which reach the wastewater in addition to remnants from the pharmaceutical industry. The presence of this hormone in the environment causes severe complications and shows high toxicity even in small amounts. It also interferes with the reproduction and development of fauna. Estradiol stimulates hormone production in mammals and changes its natural concentration in the bloodstream in addition to affecting metabolic processes [9]. Moreover, there have been reports that birds feeding on fish containing this hormone are vulnerable to their own immune system [10]. Accordingly, finding a reliable, sensitive, selective, and fast evaluation method for estradiol assessment in living organisms, food, or the environment is of the utmost importance.

There are a number of highly sensitive methods for detecting estradiol in the literature, such as high performance liquid chromatography (HPLC) [11,12], gas chromatography/mass spectrometry (GC-MS) [13,14], liquid chromatography/mass spectrometry (LC-MS) [15,16], immunoassay [17,18] and electrochemical methods [19-23]. However, the abovementioned methods have several drawbacks, such as the long sample preparation time, the high cost of the reagents used, and the requirement for well-trained personnel. The use of potentiometric sensors in the analysis enables them to get rid of these defects. These types of electrochemical sensors deserve particular attention because of their simplicity and their enhanced sensitivity of measurements [24-29].

Molecularly imprinted polymers (MIPs) have high affinity toward the target analyte. This high affinity is due to the presence of the pre-defined specific recognition cavities present in the skeleton of the MIPs. These biomimics have high stability towards $\mathrm{pH}$ changes, organic solvents and temperature. These advantages provide great flexibility in developing chemical and biological analysis methods [24-26,30,31]. Ion-selective electrodes (ISEs) based on the man-tailored imprinted polymers, MIPs, now demonstrate great attention for changing the way of using non-available ionophores [32-36]. Additionally, the membrane potential developed in ISEs does not require the template to be extracted from the skeleton of the synthesized MIP. There are also no size restrictions on the mold compound because the species should not diffuse across the membrane. Different MIPs based on MAA and EGDMA were prepared and reported for selective recognition of $17 \beta$-estradiol [37-39].

In this work, we report for the first time cost-effective, reliable and robust potentiometric ISEs for $17 \beta$-estradiol. Man-tailored biomimics for EST based on template imprinted polymers were synthesized using thermal precipitation polymerization and methacrylic acid (MAA) as an appropriate monomer. The proposed ISEs revealed a high sensitivity and selectivity for potentiometric monitoring of $17 \beta$-estradiol. The sensors were successfully applied for $17 \beta$-estradiol determination in urine and pharmaceutical formulations collected from the local market.

\section{Experimental}

\subsection{Reagents and Apparatus}

All aqueous solutions used in this work were prepared using de-ionized water (conductivity $<0.1 \mu \mathrm{S} \mathrm{cm} \mathrm{cm}^{-1}$, Millipore Milli-Q Direct-0.3 purification system). Poly(vinyl chloride) (PVC), 2-nitrophenyloctyl ether (o-NPOE), dioctylphthalate (DOP) and dibutylsebacate (DBS) were obtained from Fluka AG (Buchs, Switzerland). 17 $\beta$-Estradiol and tetradodecylammonium tetrakis (4-chlorophenyl) borate (ETH500) were purchased from Sigma Chemicals Co. (St. Louis, MO, USA). $\mathrm{Na}_{2} \mathrm{CO}_{3}, \mathrm{NaHCO}_{3}, \mathrm{NaOH}$ and $\mathrm{NaCl}$ were obtained from Acros.

A $50 \mathrm{~mm} \mathrm{HCO}_{3}{ }^{-} / \mathrm{CO}_{3}{ }^{2-}$ buffer solution of $\mathrm{pH} 10.5$ was used for all measurements to make sure that $17 \beta$-estradiol is in its ionized form. For the potentiometric selectivity study, a $1.0 \times 10^{-2} \mathrm{M}$ solution for each interfering ion was also prepared using $50 \mathrm{mM} \mathrm{HCO}_{3}{ }^{-} / \mathrm{CO}_{3}{ }^{2-}$ buffer solution, $\mathrm{pH}$ 10.5. 


\subsection{Man-Tailored Biomimics Synthesis}

Man-tailored biomimics or MIPs were prepared using the thermal precipitation polymerization method. In brief, 3.0 mmol of cross-linked MAA monomer with $3.0 \mathrm{mmol}$ of EGDMA was mixed with $1.0 \mathrm{mmol}$ of EST as a template. The mixture was mixed together and then dissolved in $15 \mathrm{~mL}$ acetonitrile. BPO $(80 \mathrm{mg})$ was added to the reaction mixture as an initiator. The cocktail was added in a $25 \mathrm{~mL}$ sealed tube. Nitrogen gas stream was diffused into the cocktail solution for $15 \mathrm{~min}$ for complete removal of dissolved oxygen. The tube was inserted in a paraffin wax at $70^{\circ} \mathrm{C}$ for $20 \mathrm{~h}$ for complete polymerization. Non-imprinted polymer (NIP) particles were prepared by the same process but without using template molecule. The resulting powders were washed after drying with absolute ethanol several times in a Soxhlet extractor for $48 \mathrm{~h}$. MIPs and NIPs were left to fully dry at room temperature before use.

\subsection{Sensor Design and Potential Measurements}

The membrane-based sensor was prepared by dissolving $64 \mathrm{mg}$ PVC, $126 \mathrm{mg}$ of the chosen plasticizer, $12 \mathrm{mg}$ of MIP or NIP particles, and $1.4 \mathrm{mg}$ ETH 500 in $3 \mathrm{~mL}$ THF. The cocktail was inserted into a glass cup ( $30 \mathrm{~mm}$ i.d.) and left overnight until complete evaporation of THF. A disk of about $6 \mathrm{~mm}$ in diameter was then cut and glued by THF to a piece of Tygon tube ( $5 \mathrm{~mm}$ in inner diameter, $9 \mathrm{~mm}$ in outer diameter and $2 \mathrm{~cm}$ in length). The Tygon tube was attached to a plastic electrode body, and a 1:1 mixture of $10^{-2} \mathrm{M} \mathrm{NaCl}$ solution and $1 \mathrm{mM} 17 \beta$-estradiol solution (buffered with $50 \mathrm{mM} \mathrm{HCO}{ }^{-} / \mathrm{CO}_{3}{ }^{2-}$ buffer solution, $\mathrm{pH}$ 10.5) was used as internal filling solution. An internal reference electrode made from $\mathrm{Ag} / \mathrm{AgCl}$ was inserted in the filling solution for electrical connection. The potential response versus an external $\mathrm{Ag} / \mathrm{AgCl}$ double junction reference electrode was recorded.

The prepared ISEs were inserted for $6 \mathrm{~h}$ in $1 \mathrm{mM}$ of EST solution ( $\mathrm{pH}$ 10.5) for conditioning. Test solution was kept at $\mathrm{pH} 10.5$ using $50 \mathrm{mM} \mathrm{HCO}_{3}{ }^{-} / \mathrm{CO}_{3}{ }^{2-}$ buffer solution. The potential of the solutions was recorded over different concentration range of EST solution to construct the calibration plot.

\subsection{Estradiol Assessment}

The applicability of the proposed ISEs was tested in different urine samples. A $10 \mathrm{~mL}$ aliquot of different urine samples was transferred to a $100 \mathrm{~mL}$ measuring flask and then diluted to the mark using $50 \mathrm{mM} \mathrm{HCO}_{3}{ }^{-} / \mathrm{CO}_{3}{ }^{2-}$ buffer solution, $\mathrm{pH} 10.5$. A $1.0 \mathrm{~mL}$ aliquot of EST solution to cover the range from 2 to $10 \mu \mathrm{M}$ was transferred to a $20 \mathrm{~mL}$ beaker containing $9 \mathrm{~mL}$ of $50 \mathrm{mM} \mathrm{HCO}{ }_{3}{ }^{-} / \mathrm{CO}_{3}{ }^{2-}$ buffer solution, $\mathrm{pH}$ 10.5. The sensor was immersed in conjunction with the reference electrode in the test solution. Possible readings were recorded after the equilibrium response was reached and compared with the calibration graph.

Estradiol was also analyzed using the proposed ISEs in different commercially available drugs: Estraderm ( $50 \mathrm{mg} /$ tablet, Novaris pharmaceuticals, Cairo, Egypt) and Oestrogel ( $0.06 \% w / w$, Gel, Besins). To examine estradiol in tablet formulations, 3 tablets were ground in an agate mortar. A specified amount of 3 finely mixed powder disks, equivalent to one tablet, was transferred to a $100 \mathrm{~mL}$ volumetric flask and dissolved in $20 \mathrm{~mL}$ aqueous $\mathrm{NaOH}$ solution $(0.1 \mathrm{M})$, sonicated for $45 \mathrm{~min}$. The solution is then adjusted to $\mathrm{pH} 10.5$ with $50 \mathrm{mM} \mathrm{HCO}{ }_{3}{ }^{-} / \mathrm{CO}_{3}{ }^{2-}$ buffer solution and then supplemented to the mark. Possible measurements of these solutions were carried out and the potential readings were recorded and compared to the constructed calibration plot. The preparation of the gel sample was followed by weighting the appropriate amount of the drug as well as dissolving it in a solution of $20 \mathrm{~mL}$ aqueous $\mathrm{NaOH}$ solution $(0.1 \mathrm{M})$.

\section{Results and Discussions}

Herein, we presented, for the first time, a simple and sensitive analytical system based on MIPs for the assessment of $17 \beta$-estradiol (EST). For this purpose, we introduced an electrochemical sensor 
utilizing the potentiometric transduction of bound EST to the MIPs by electrochemical reaction. A schematic illustration for the molecular imprinting process is shown in Figure 1.
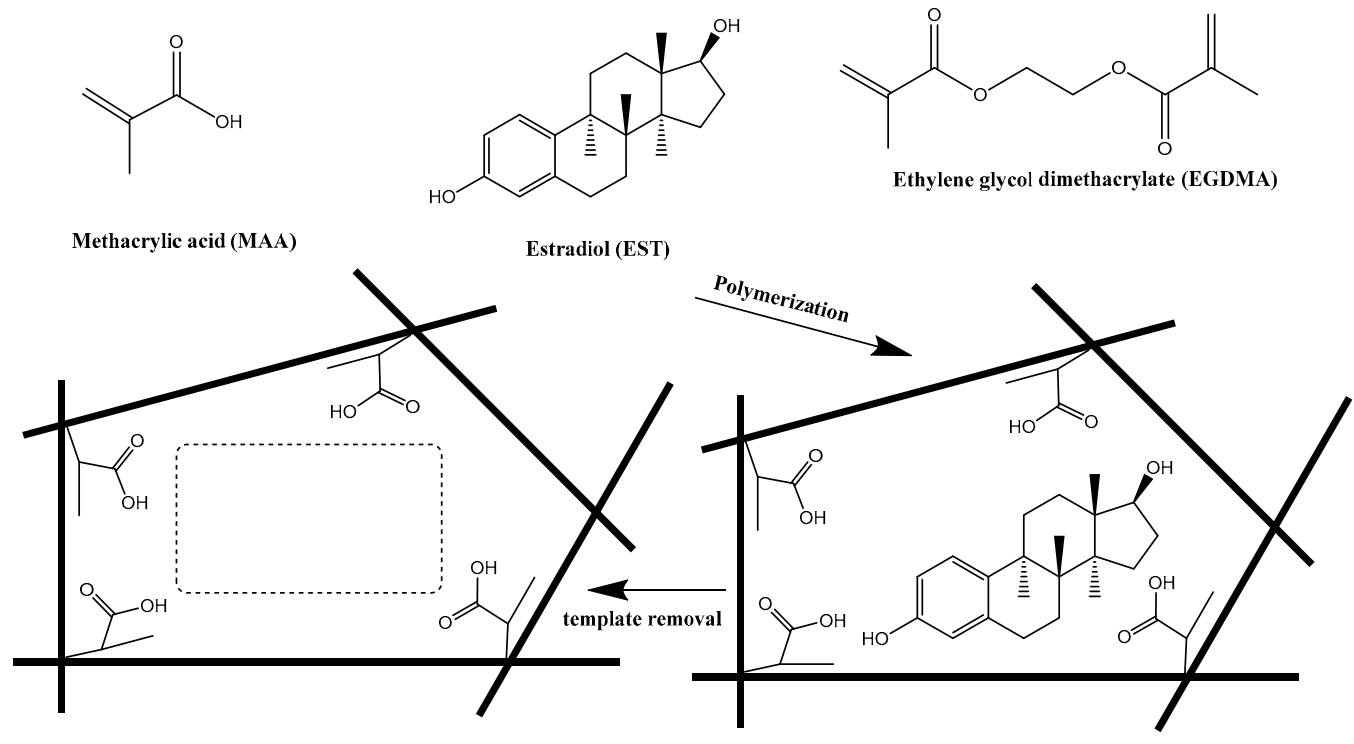

Figure 1. Protocol of synthesis of molecularly imprinted polymers (MIPs) and its recognition towards $17 \beta$-estradiol.

\subsection{SEM Analysis of Biomimic Particles}

The morphological forms of both MIP and NIP surfaces were examined using an electronic scanning microscope (SEM) (Figure 2). Figure 2A presents a medium uniformity with a spherical shape for the NIP particles with an average diameter of about $1.8 \mu \mathrm{m}$. For the MIP particles, the surface morphology presented in Figure 2B showed irregular beads with a mean diameter of $0.7 \mu \mathrm{m}$. The different surface morphologies between MIP and NIP particles confirm the tracing of the printing process that ensures the MIP efficiency as a suitable ionophore for the recognition of estradiol in the presented sensors.

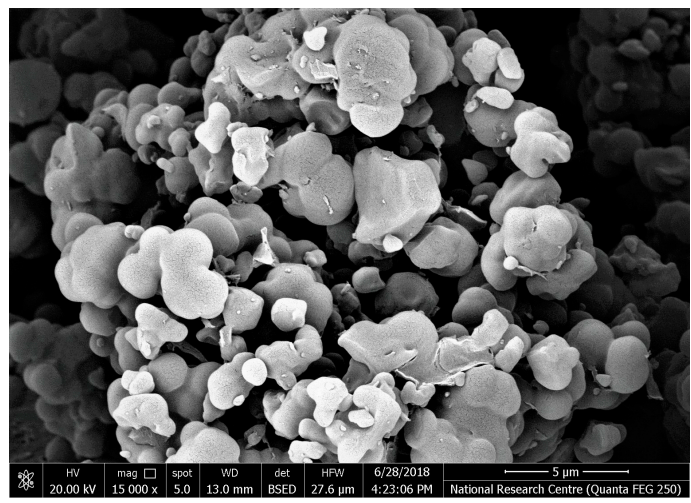

(A)

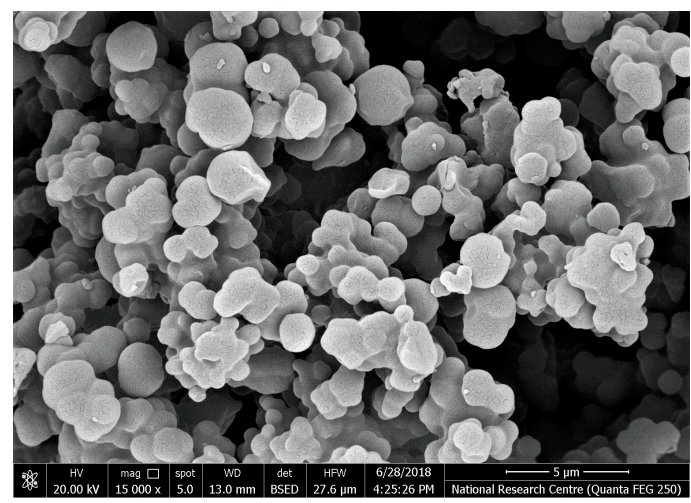

(B)

Figure 2. Scanning electron microscope (SEM) images of (A) non-imprinted polymer (NIP) beads and (B) washed MIP beads.

\subsection{Potentiometric Detection of EST}

A novel PVC membrane sensor based on a newly synthesized MIP particles as a sensory recognition material, dibutylsebacate (DBS), dioctylphthalate (DOP) or o-nitrophenyloctyl ether (o-NPOE) as a solvent mediator, and $\mathrm{PVC}$ as polymeric matrix was prepared and tested as an ion sensor for detecting 
$17 \beta$-estradiol. The polarity of the membrane solvent not only affects the dissolution of the ionophore in the membrane but also can affect the movement of the ion in the membrane phase. Hence, membrane optimization should be considered in this study. Different plasticizers with different polarities were investigated and their influences on the potential response of the sensing membrane were recorded. As shown in Table 1, a membrane incorporating $o$-NPOE plasticizer (high dielectric constant, $\varepsilon=24$ ) showed the best characteristics. The sensors display a linear response starts from $2.5 \mu \mathrm{M}$ with an anionic response with a slope of $61.2 \pm 1.2 \mathrm{mV} /$ decade and a detection limit of $1.5 \mu \mathrm{M}(3 \sigma)$. As shown in Figure 3, better response behavior and better sensitivity was obtained with the polar plasticizer $o$-NPOE. This can be explained on the basis that EST prefers the high polar solvent to be distributed into the sensing membrane. The potential response of the proposed sensor towards EST is shown in Figure 4. The potential difference between baseline potential and those measured at a specific time (i.e., $120 \mathrm{~s}$ ) was used after the addition of the EST for quantitative analysis. The presented sensor revealed fast response and stable potential. As a control, sensors based on NIP beads were also tested. These sensors possessed a linear range starts from $10 \mu \mathrm{M}$ with a slope of $-15.6 \pm 1.5 \mathrm{mV} /$ decade $\left(\mathrm{R}^{2}=0.991\right)$ and a detection limit of $8.5 \mu \mathrm{g} / \mathrm{mL}$. The sensing mechanism of $17 \beta$-estradiol using MAAand EGDMA-based MIPs is illustrated in Figure 5.

Table 1. Performance characteristics of $17 \beta$-estradiol PVC membrane sensor in $50 \mathrm{mM} \mathrm{HCO}{ }^{-} / \mathrm{CO}_{3}{ }^{2-}$ (pH 10.5).

\begin{tabular}{cccc}
\hline Parameter & MIP/o-NPOE & MIP/DOP & MIP/DBS \\
\hline Lower limit of linear range, $\boldsymbol{\mu M}$ & 2.5 & 4.8 & 6.2 \\
Slope, $\mathbf{m V}$ /log [EST] & $-61.2 \pm 1.2$ & $-52.6 \pm 2.2$ & $-31.6 \pm 1.8$ \\
Low detection limit, $\boldsymbol{\mu M}$ & 1.5 & 3.2 & 4.3 \\
Correlation coefficient, $\mathbf{r}^{\mathbf{2}}$ & 0.9995 & 0.991 & 0.993 \\
Response time, $\mathbf{s}$ & $<10$ & $<10$ & $<10$ \\
Accuracy, \% & 99.3 & 98.7 & 97.3 \\
Trueness, \% & 99.5 & 99.1 & 97.2 \\
Bias, \% & 0.4 & 0.6 & 1.3 \\
Within-day repeatability, $\mathbf{C V}_{\mathbf{w}} \mathbf{\%}$ & 1.1 & 0.9 & 1.4 \\
Between-days variation, $\mathbf{C V}_{\mathbf{b}} \mathbf{\%}$ & 1.2 & 0.7 & 1.2 \\
\hline
\end{tabular}

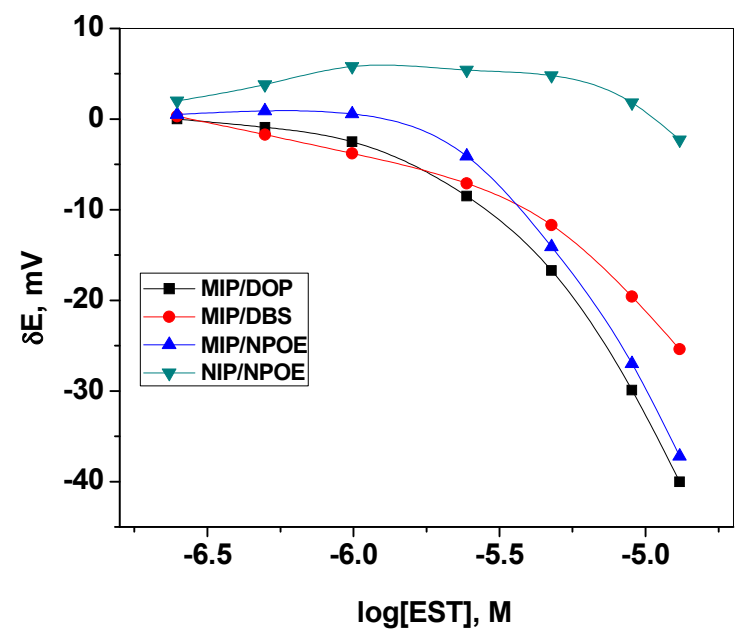

Figure 3. Effect of plasticizer type on the membrane response. 


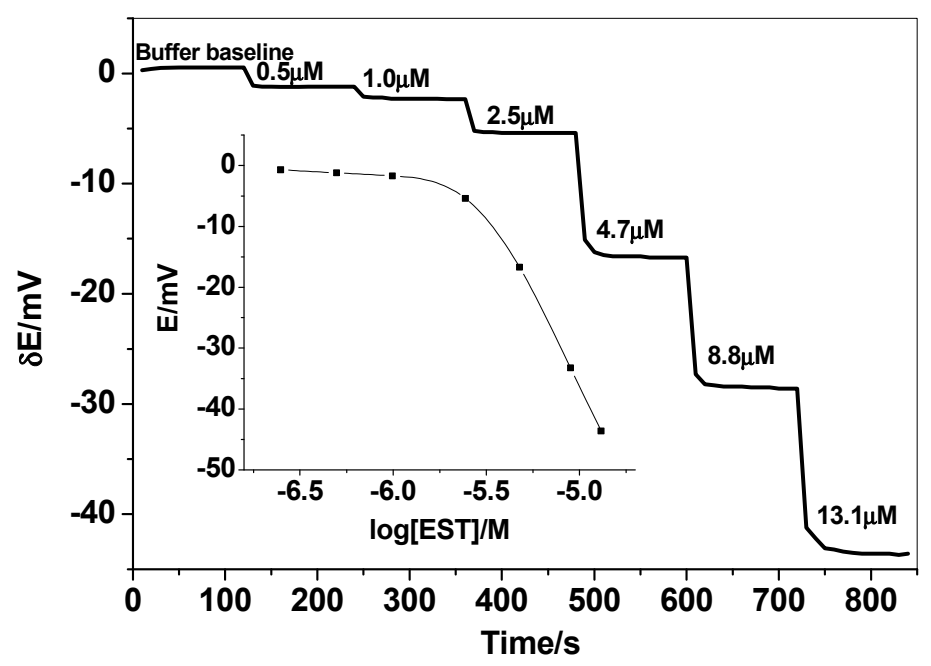

Figure 4. The dynamic potentiometric responses of $17 \beta$-estradiol (EST)-based sensor in $50 \mathrm{mM}$ $\mathrm{HCO}_{3}{ }^{-} / \mathrm{CO}_{3}{ }^{2-}$ buffer solution, $\mathrm{pH} 10.5$. The inset shows the measuring calibration plot for EST.

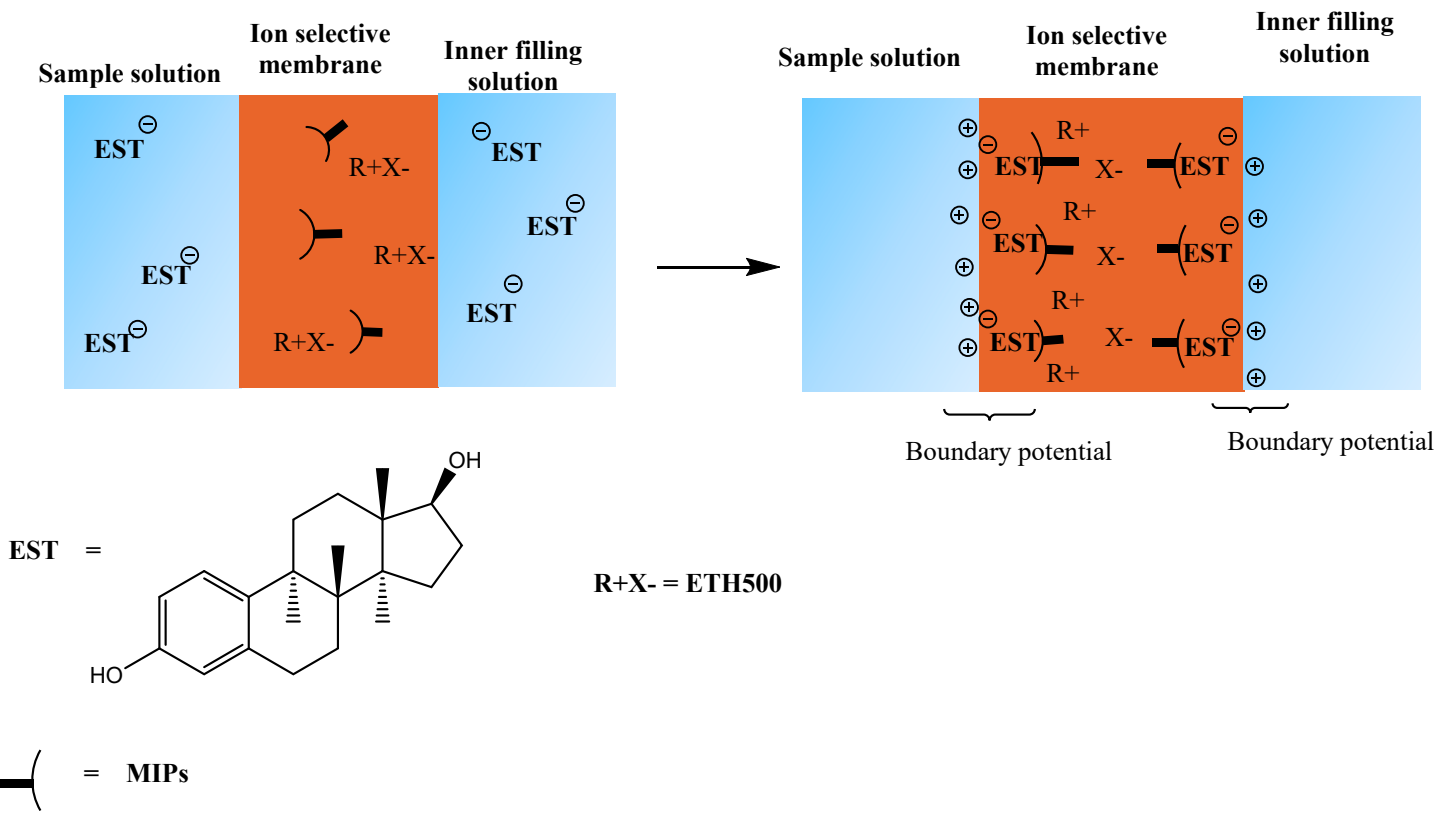

Figure 5. Response mechanism of the proposed $17 \beta$-estradiol sensor.

\subsection{Sensor Selectivity}

The selectivity coefficient values of the proposed sensors were evaluated using the so-called "modified separate solution method (MSSM)" [40]. The potential responses towards EST were recorded as shown in Figure 6. The pKa values for phenol derivatives used in selectivity measurements lie in the range 7.8-10.5. Hence, $\mathrm{pH} 10.5$ is the selected value to ensure the presence of the ionized form of these compounds. Experiments have shown that the selectivity arrangement of the MIP-based sensor is EST > 2-chlorophenol > 2,4-dichlorophenol > 2-naphthol > 3-nitrophenol > 2-nitrophenol > p-cresol. The selectivity order of these neutral phenols reflects their acidity and lipophilicity [41]. As the acidity and lipophilicity increases, the anionic response increases. Partition coefficients and acid dissociation constants of EST, 2-chlorophenol, 2,4-dichlorophenol, 2-naphthol, 3-nitrophenol, 2-nitrophenol and p-cresol are and 4.01, 2.15, 3.06, 2.7, 2.0, 1.79 and 1.94, and 10.07, 8.52, 7.89, 9.5, 8.3, 7.23, and 10.3, respectively [41]. 


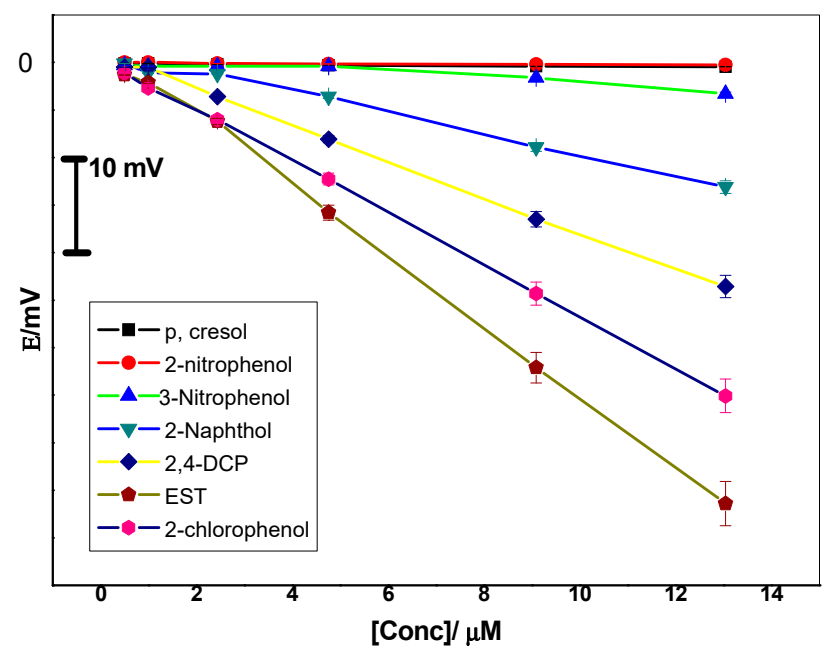

Figure 6. Potentiometric selectivity of MIP membrane-based sensors towards $17 \beta$-estradiol (EST).

\subsection{Analytical Applications}

The applicability of the proposed ISEs for EST determination was checked in urine samples.

However, sample dilution can be used to avoid the effect of the matrix. Adsorption of urine protein onto the PVC membrane in the sensors leads to poor reproducibility. Determination of EST was performed in biological fluids using the proposed estradiol probes. The potential responses of urine samples in 30mM PBS buffer of pH 7.0 and containing fixed concentration of estradiol were measured directly. The results showed an average mean recovery of $94.0-101.2 \%$ (Table 2) indicating minimal interference effect due to the matrix. Estradiol was determined using the standard addition method in two commercially available medicines collected from the domestic market. The results obtained with measured recovery for each drug are presented in Table 3. A measured recovery between 90 and $102.4 \%$ indicates that the proposed method for determining estradiol using the displayed electrode is appropriate for pharmaceutical analysis. From the obtained results by the proposed potentiometric method, it was compared to those obtained by the HPLC method [42]. The results of the $t$-Student and $F$-test confirmed that there were no statistically significant differences between the results of the two methods and revealed the successful application of the proposed ISE as a new analytical method for determining EST.

Table 2. Determination of EST in spiked urine samples using o-NPOE plasticized membrane sensors.

\begin{tabular}{cccc}
\hline \multirow{2}{*}{ Sample } & \multicolumn{3}{c}{ EST Added, $\mu \mathbf{M}$} \\
\cline { 2 - 4 } & Added & Found * & Recovery, \% \\
\hline $\mathbf{1}$ & 2.5 & $2.4 \pm 0.3$ & 96 \\
$\mathbf{2}$ & 5 & $4.7 \pm 0.5$ & 94 \\
$\mathbf{3}$ & 8 & $8.1 \pm 0.8$ & 101.2 \\
\hline \multicolumn{4}{c}{}
\end{tabular}

Table 3. EST determination in pharmaceutical preparations using EST membrane sensor.

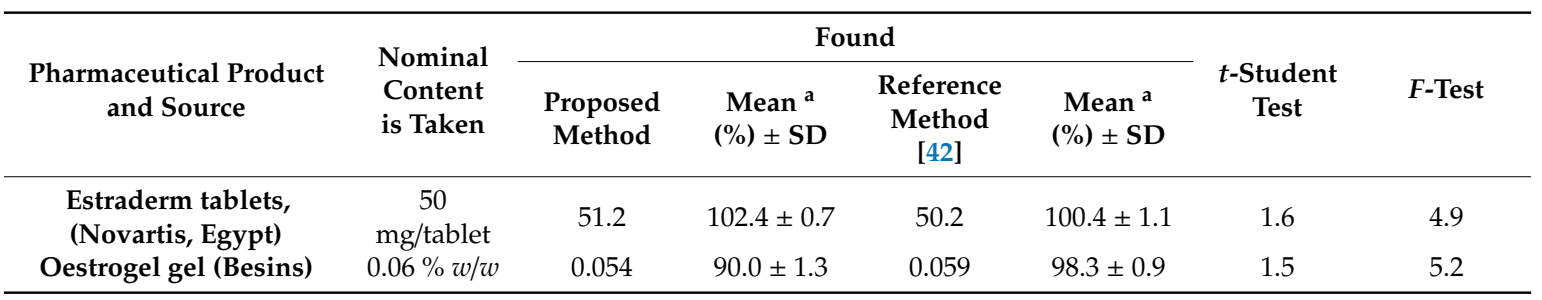

${ }^{a}$ Mean of three replicate measurements \pm standard deviation (SD). $t$-Student and $F$-test at $95 \%$ confidence level values are 4.30 and 19.00 , respectively. 


\section{Conclusions}

A reliable, robust, and cost-effective potentiometric sensor based on man-tailored mimics for the potentiometric transduction of estradiol has been presented. The MIP particles are dispersed into a plasticized PVC membrane. The ISEs displayed extended linear response range starts from $2.5 \mu \mathrm{M}$, low detection limit $1.5 \mu \mathrm{M}$ and fast response time $(<10 \mathrm{~s})$. The presented electrodes revealed good advantages over many of those previously described in terms of durability, ease of manufacture, potential stability, selectivity, and accuracy. The proposed liquid contact estradiol-sensor was successfully used for trace determination of $17 \beta$-estradiol in different pharmaceutical formulations and urine samples. No sample pretreatment is required for estradiol analysis using these proposed ISEs.

Author Contributions: A.H.K., H.R.G. and A.E.-G.E.A. conceptualized the study, interpreted the results, carried out the experiments, and prepared the manuscript; A.H.K. and A.E.-G.E.A. cooperated in the preparation of the manuscript; E.A.E, A.E.-G.E.A., and A.I.A.-S. performed the clinical studies. All authors have read and agreed to the published version of the manuscript.

Funding: The authors are grateful to the Deanship of Scientific Research, King Saud University for funding this work through Research Group Project "RGP-1435-047".

Conflicts of Interest: The authors declare no conflicts of interest.

\section{References}

1. Brunton, L.L.; Lazo, J.S.; Parker, K.L. The Pharmacological Basis of Therapeutics, 11th ed.; McGraw-Hill: New York, NY, USA, 2005; p. 2021.

2. Mutschler, E.; Gesslinger, G.; Kroemer, H.K.P.; Ruth, P.; Schäfer-Korting, M. Farmakologia I Toksykologia; MedPharm: Wrocław, Poland, 2010.

3. Guyton, A.C. Textbook of Medical Physiology, 11th ed.; W.B. Saunders: Philadelphia, PA, USA, 2006.

4. Wang, Z.; Wang, P.; Tu, X.; Wu, Y.; Zhan, G.; Li, C. A novel electrochemical sensor for estradiol based on nanoporous polymeric film bearing poly\{1-butyl-3-[3-(N-pyrrole)propyl]imidazole dodecyl sulfonate\} moiety. Sens. Actuators B 2014, 193, 190-197. [CrossRef]

5. Han, Q.; Shen, X.; Zhu, W.; Zhu, C.; Zhou, X.; Jiang, H. Magnetic sensing film based on $\mathrm{Fe}_{3} \mathrm{O}_{4} @ \mathrm{Au}-\mathrm{GSH}$ molecularly imprinted polymers for the electrochemical detection of estradiol. Biosens. Bioelectron. 2016, 79, 180-186. [CrossRef]

6. Vale, N.; Gouveia, M.J.; Rinaldi, G.; Santos, J.; Santos, L.L.; Brindley, P.J.; da Costa, J.M.C. The role of estradiol metabolism in urogenital schistosomiasis-induced bladder cancer. Tumor Biol. 2017, 39, 1-11. [CrossRef] [PubMed]

7. Lan, Y.L.; Zou, S.; Zhang, C.; Li, J.; Xu, Y.; Li, S. Update on the effect of estradiol in postmenopause women with Alzheimer's disease: A systematic review. Acta Neurol. Belg. 2016, 116, 249-257. [CrossRef]

8. Kwakowsky, A.; Milne, M.; Waldvogel, H.; Faull, R. Effect of estradiol on neurotroph in receptors in basal forebrain cholinergic neurons: Relevance for Alzheimer's disease. Int. J. Mol. Sci. 2016, 17, 2122. [CrossRef]

9. Palmeri, R.; Grimaudo, S. Estradiol: Synthesis, Health Effects and Drug Interactions; Nova Science Publishers Incorporated: New York, NY, USA, 2013; p. 319.

10. Ying, G.G.; Kookana, R.S.; Ru, Y.J. Occurrence and fate of hormone steroids in the environment. Environ. Int. 2002, 28, 545-551. [CrossRef]

11. Yoon, Y.; Westerhoff, P.; Snyder, S.A.; Esparz, M. HPLC-fluorescence detection and adsorption of bisphenol A, $17 \beta$-estradiol, and $17 \alpha$-ethynyl estradiol on powdered activated carbon. Water Res. 2003, 37, 3530-3537. [CrossRef]

12. Geisler, J.; Berntsen, H.; Lønning, P.E. A novel HPLC-RIA method for the simultaneous detection of estrone, estradiol and estrone sulphate levels in breast cancer tissue. J. Steroid Biochem. Mol. Biol. 2000, 72, 259-264. [CrossRef]

13. Lee, H.B.; Peart, T.E. Determination of 17 beta-estradiol and its metabolites in sewage effluent by solid-phase extraction and gas chromatography/mass spectrometry. J. AOAC Int. 1998, 81, 1209-1216. [CrossRef]

14. Santen, R.J.; Demers, L.; Ohorodnik, S.; Settlage, J.; Langecker, P.; Blanchett, D.; Goss, P.E.; Wang, S. Superiority of gas chromatography/tandem mass spectrometry assay (GC/MS/MS) for estradiol for monitoring of aromatase inhibitor therapy. Steroids 2007, 72, 666-671. [CrossRef] 
15. Nelson, R.E.; Grebe, S.K.; O'Kane, D.J.; Singh, R.J. Liquid chromatography-tandem mass spectrometry assay for simultaneous measurement of estradiol and estrone in human plasma. Clin. Chem. 2004, 50, 373-384. [CrossRef]

16. Xu, X.; Roman, J.M.; Issaq, H.J.; Keefer, L.K.; Veenstra, T.D.; Ziegler, R.G. Quantitative measurement of endogenous estrogens and estrogen metabolites in human serum by liquid Chromatography-Tandem mass spectrometry. Anal. Chem. 2007, 79, 7813-7821. [CrossRef]

17. Hintemann, T.; Schneider, C.; HSchöler, H.F.; Schneider, R.J. Field study using two immunoassays for the determination of estradiol and ethinylestradiol in the aquatic environment. Water Res. 2006, 40, 2287-2294. [CrossRef]

18. Zhao, L.; Lin, J.M.; Li, Z.; Ying, X. Development of a highly sensitive, second antibody format chemiluminescence enzyme immunoassay for the determination of $17 \beta$-estradiol in wastewater. Anal. Chim. Acta 2006, 558, 290-295. [CrossRef]

19. Olowu, R.A.; Arotiba, O.; Mailu, S.N.; Waryo, T.T.; Baker, P.; Iwuoha, E. Electrochemical aptasensor for endocrine disrupting $17 \beta$-estradiol based on a poly (3,4-ethylenedioxylthiopene)-gold nanocomposite platform. Sensors 2010, 10, 9872-9890. [CrossRef]

20. Li, J.; Liu, S.; Yu, J.; Lian, W.; Cui, M.; Xu, W.; Huang, J. Electrochemical immunosensor based on graphene-polyanilinecomposites and carboxylated graphene oxide for estradiol detection. Sensors Actuators. B Chem. 2013, 188, 99-105.

21. Smajdor, J.; Piech, R.; Ławrywianiec, M.; Paczosa-Bator, B. Glassy carbon electrode modified with carbon black for sensitive estradiol determination by means of voltammetry and flow injection analysis with amperometric detection. Anal. Biochem. 2018, 544, 7-12. [CrossRef]

22. Wong, A.; Santos, A.M.; Fava, E.L.; Fatibello-Filho, O.; Sotomayor, M.D.T. Voltammetric determination of $17 \beta$-estradiol in different matrices using a screen-printed sensor modified with CuPc, Printex $6 \mathrm{~L}$ carbon and Nafion film. Microchem. J. 2019, 147, 365-373. [CrossRef]

23. Masikini, M.; Ghica, M.E.; Baker, P.G.L.; Iwuoha, E.I.; Brett, C.M.A. Electrochemical Sensor Based on Multi-walled Carbon Nanotube/Gold Nanoparticle Modified Glassy Carbon Electrode for Detection of Estradiol in Environmental Samples. Electroanalysis 2019, 31, 1925-1933. [CrossRef]

24. Kamel, A.H.; Jiang, X.; Li, P.; Liang, R. A paper-based potentiometric sensing platform based on molecularly imprinted nanobeads for determination of bisphenol A. Anal. Methods 2018, 10, 3890-3895. [CrossRef]

25. El-Kosasy, A.; Kamel, A.H.; Hussin, L.; Ayad, M.F.; Fares, N. Mimicking new receptors based on molecular imprinting and their application to potentiometric assessment of 2,4-dichlorophenol as a food taint. Food Chem. 2018, 250, 188-196. [CrossRef]

26. Kamel, A.H.; Hassan, A.M.E. Solid Contact Potentiometric Sensors Based on Host-Tailored Molecularly Imprinted Polymers for Creatine Assessment. Int. J. Electrochem. Sci. 2016, 11, 8938-8949. [CrossRef]

27. Hassan, S.S.M.; Marzouk, S.A.M.; Mohamed, A.H.K.; Badawy, N.M. Novel dicyanoargentate polymeric membrane sensors for selective determination of cyanide ions. Electroanalysis 2004, 16, 298-303. [CrossRef]

28. Hassan, S.S.M.; Mahmoud, W.H.; Mohamed, A.H.K.; Kelany, A.E. Mercury(II) Ion-Selective Polymeric Membrane Sensors for Analysis of Mercury in Hazardous Wastes. Anal. Sci. 2006, 22, 877-881. [CrossRef] [PubMed]

29. Hassan, S.S.M.; Badr, I.H.A.; Kamel, A.H.; Mohamed, M.S. A Novel Poly (Vinyl Chloride) Matrix Membrane Sensor for Batch and Flow-injection Determination of Thiocyanate, Cyanide and Some Metal Ions. Anal. Sci. 2009, 25, 911-917. [CrossRef] [PubMed]

30. El-Naby, E.H.; Kamel, A.H. Potential transducers based man-tailored biomimetic sensors for selective recognition of dextromethorphan as an antitussive drug. Mater. Sci. Eng. C 2015, 54, 217-224. [CrossRef]

31. Abdalla, N.S.; Youssef, M.A.; Algarni, H.; Awwad, N.S.; Kamel, A.H. All solid-state poly (vinyl chloride) membrane potentiometric sensor integrated with nano-beads imprinted polymers for sensitive and rapid detection of bispyribac herbicide as organic pollutant. Molecules 2019, 24, 712. [CrossRef] [PubMed]

32. Hassan SS, M.; Amr AE, G.E.; El-Naby, H.A.; El-Naggar, M.; Kamel, A.H.; Khalifa, N.M. Novel aminoacridine sensors based on molecularly imprinted hybrid polymeric membranes for static and hydrodynamic drug quality control monitoring. Materials 2019, 12, 3327. [CrossRef]

33. Moreira, F.T.C.; Guerreiro, J.R.L.; Vera, L.O.; Azevedo, L.O.V.; Kamel, A.H.; Sales, M.G.F. New potentiometric sensors for the determination of tetracycline in biological samples: Batch and flow mode operations. Anal. Meth. 2010, 2, 2039. [CrossRef] 
34. Abdalla, N.S.; Amr, A.E.; El-Tantawy, A.S.M.; Al-Omar, M.A.; Kamel, A.H.; Khalifa, N.M. Tailor-Made Specific Recognition of Cyromazine Pesticide Integrated in a Potentiometric Strip Cell for Environmental and Food Analysis. Polymers 2019, 11, 1526. [CrossRef]

35. Ezzat, S.; Ahmed, M.A.; Amr, A.E.; Al-Omar, M.A.; Kamel, A.H.; Khalifa, N.M. Single-Piece All-Solid-State Potential Ion-Selective Electrodes Integrated with Molecularly Imprinted Polymers (MIPs) for Neutral 2, 4-Dichlorophenol Assessment. Materials 2019, 12, 2924. [CrossRef]

36. Kamel, A.H.; Soror, T.Y.; Al-Romian, F.M. Flow through potentiometric sensors based on molecularly imprinted polymers for selective monitoring of mepiquat residue, a quaternary ammonium herbicide. Anal. Meth. 2012, 4, 3007-3012. [CrossRef]

37. Le Noir, M.; Lepeuple, A.; Guieysse, B.; Mattiasson, B. Selective removal of $17 \mathrm{~b}$-estradiol at trace concentration using a molecularly imprinted polymer. Water Res. 2007, 41, 2825-2831. [CrossRef]

38. Jiang, T.; Zhao, L.; Chu, B.; Feng, Q.; Yan, W.; Lin, J. Molecularly imprinted solid-phase extraction for the selective determination of $17 \beta$-estradiol in fishery samples with high performance liquid chromatography. Talanta 2009, 78, 442-447. [CrossRef] [PubMed]

39. DeMaleki, Z.; Lai, E.P.C.; Dabek-Zlotorzynska, E. Capillary electrophoresis characterization of molecularly imprinted polymer particles in fast binding with 17b-estradiol. J. Sep. Sci. 2010, 33, 2796-2803. [CrossRef] [PubMed]

40. Bakker, E. Determination of improved selectivity coefficients of polymer membrane ion-selective electrodes by conditioning with a discriminated ion. J. Electrochem. Soc. 1996, 143, L83-L85. [CrossRef]

41. PubChem. Available online: https://pubchem.ncbi.nlm.nih.gov (accessed on 11 August 2019).

42. British Pharmacopoeia Commission. British Pharmacopoeia 2009; The Stationery Office 1: London, UK, 2009 ; p. 2.

(C) 2020 by the authors. Licensee MDPI, Basel, Switzerland. This article is an open access article distributed under the terms and conditions of the Creative Commons Attribution (CC BY) license (http://creativecommons.org/licenses/by/4.0/). 